\title{
FURTHER STUDIES ON PHYSIOLOGICAL STATES AND RHEOTAXIS IN ISOPODA
}

\author{
W. C. ALLEE \\ The University of Illinois \\ NINE FIGURES \\ CONTENTS
}

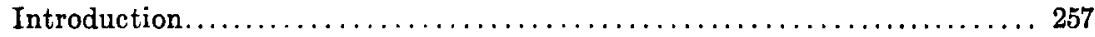

1. Stock......................................... 259

Response to concussion compared with the sign and efficiency of the rheo-

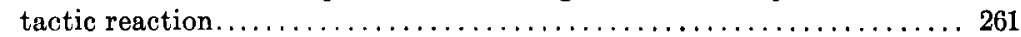





Daily variations in the rheotactic reaction $\ldots \ldots \ldots \ldots \ldots \ldots \ldots \ldots \ldots, \ldots \ldots$

1. Question of a daily rhythm. ........................ 278

Effect of low oxygen and potassium cyanide on the reactions of individual

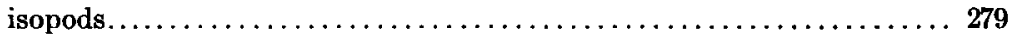

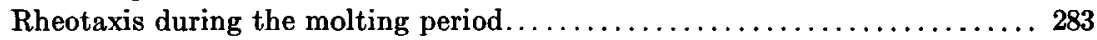

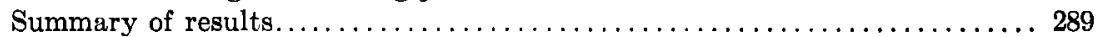



Bibliography. . . . . . . . . . . . . . . . . . . . . . . . . . . . . . . 294

\section{INTRODUCTION}

This is the second of a proposed series of experimental studies upon the relation between physiological states and rheotaxis in the isopod Asellus communis Say. In an earlier paper (Allee '12) I showed that the species A. communis is composed of pond and stream mores (Shelford ' 11 a). These mores are easily distinguished, since when tested in a circular current the normal stream isopods give a high percentage, while those from ponds give a low percentage of positive rheotactic responses. Experiments have shown that conditions that are known to depress the rate of metabolism decrease the percentage of positive responses given by stream isopods. The depressing 257

THE JOURNAL OF EXPERMENTAL zOÖLOGY, YOL. 15, NO. 3

OCTOBER, 1913 
conditions used experimentally were: low oxygen, chloretone, potassium cyanide, low temperature, sudden extreme increase of temperature, increased carbon dioxide, and starvation. On the other hand, atmospheric or complete saturation of oxygen, caffein, and an increase of temperature if not too extreme, caused the pond isopods to give a higher percentage of positive responses. These last conditions are known to increase the metabolic rate of the organism.

All this first work was done on groups of isopods selected at random from the general stock. Usually from five to eight were tested at the same time and the averaged results from ten successive trials were taken as representing the condition of the group under experimentation. The present series of experiments deals with the individual isopod rather than the group. In order to give time for more intensive study these experiments deal with individuals of the stream mores only. They were conducted to throw light on the following questions:

1. What is the relation between the efficiency of movement in the current and the sign of response in rheotactic reactions?

2 . Is there any relation between the reaction to a uniform shock stimulus and the sign of the rheotactic response, or the efficiency of that response?

3. How great a variation is there in the rheotactic reaction of individual isopods kept in uniform conditions?

4. What is the effect of the depressing agents, potassium cyanide and low oxygen, upon the rheotactic and shock reactions of the individual isopods?

5. What is the effect of the molting period upon rheotaxis?

These experiments are being prosecuted from the ecological point of view. The term 'ecology,' as I understand it, means that portion of general physiology which has for its problem the relation between the organism and its complete environment (cf. Semper '81, pp. 25-35; Shelford '12 c, pp. 333-34) I fully agree with Shelford ('12 c, p. 365) that the ecologist must specialize upon some aspect of the subject, because it is unusually large and its concepts unusually complex. Since the data as collected in field observations are so complex and since there 
are so few who are prepared to make field observations and to fill in logically the inevitable gaps in such data, it seems the more important that ecological views be subjected to the most rigorous experimental tests before they are accepted.

Fortunately there is a large mass of data that has been collected in the fields of general physiology and general psychology, called 'animal behavior,' upon which the ecologist may draw. But unfortunately for the ecologist, most of this experimental work has been done either from the standpoint of the physiologist, where a minimum of emphasis is placed upon the natural environment and a maximum upon the method of the reaction (Loeb '05; Jennings '06 and Mast '11); or from the standpoint of the comparative psychologist (Holmes '11). It is true that even in much of this work the idea of response to environment is present, sometimes in a marked degree, as with Dawson ('11) and more rarely it is the dominant thought (Shelford and Allee '13).

\section{STOCK}

The isopods were all Asellus communis of a stock collected in County Line Creek (Shelford '11 a, maps) near Glencoe, Illinois. They belong to the same general stock which furnished material for almost all the earlier experiments on stream isopods. After being kept in an aquarium supplied with Chicago city tap water, at the University of Chicago for a year the isopods were transferred to the University of Illinois and placed in aerated ${ }^{1}$ university tap water. The chemical analyses of the two waters are shown in table 1.

The change in water did not greatly affect the rheotactic reaction of the isopods. One lot received October 24, 1912, which had been two days in transit in small containers, gave an average of 62 per cent positive for 150 trials when first received. Four days later the positive response had increased to

1 The aeration was accomplished either by allowing the water to flow slowly through a series of pans (Marsh '10) or by allowing air from the university compressed air system to bubble through small openings in a rubber tube laid around the bottom of the aquarium. 
TABLE 1

A comparison of chemical analyses of Chicago and University of Illinois tap water. Analyses of solids in parts per million and gases in cubic centimeter per liter

\begin{tabular}{|c|c|c|}
\hline & CHICAGO TAPI & V. OF $\mathrm{X}$. TAP \\
\hline Potassium, K. & $6.0^{3}$ & 2.6 \\
\hline Sodium, Na.... & $42.1^{3}$ & 29.0 \\
\hline Ammonium, $\mathrm{NH}_{4} \ldots \ldots \ldots \ldots \ldots$ & 0.04 & 2.3 \\
\hline Magnesium, $\mathrm{Mg} \ldots \ldots \ldots \ldots \ldots \ldots$ & 11.3 & 34.9 \\
\hline Calcium, Ca.. & 34.6 & 70.1 \\
\hline Iron, Fe.......... & 0.15 & 1.0 \\
\hline Aluminum, $\mathrm{Al} \ldots \ldots \ldots \ldots \ldots \ldots \ldots$ & 0.00 & 1.3 \\
\hline Silica, $\mathbf{S i} \ldots \ldots \ldots \ldots \ldots \ldots \ldots \ldots$ & $3.3^{3}$ & 18.9 \\
\hline Nitrate, $\mathrm{NO}_{3} .$. & 1.7 & 0.7 \\
\hline Chlorine, $\mathrm{Cl}$. . & 12.0 & 3.5 \\
\hline Lead, $\mathrm{Pb} \ldots \ldots \ldots \ldots \ldots \ldots \ldots \ldots \ldots$ & 0.01 & 0.00 \\
\hline Sulphuric acid, $\mathrm{SO}_{3} \ldots \ldots \ldots \ldots \ldots$ & 0.04 & 2.3 \\
\hline Oxygen, $0 \ldots \ldots \ldots \ldots \ldots \ldots \ldots \ldots$ & 10.46 & $0.12^{4}$ \\
\hline Free carbon dioxide $\ldots \ldots \ldots \ldots \ldots \ldots$ & 2.5 & 18.0 \\
\hline Half bound carbon dioxide........... & 32.5 & 101.12 \\
\hline
\end{tabular}

${ }^{1}$ Shelford and Allee '13, table 4, p. 217.

${ }^{2}$ Bartow '06, p. 34.

${ }^{3}$ Bartow.

4 After allowing air to bubble through the water, the dissolved oxygen was raised to air saturation ( 5.5 to 7 cc. per liter). The free carbon dioxide was removed and the half bound carbon dioxide was reduced to $88.58 \mathrm{cc}$. per liter.

71 per cent of 150 trials, and seven days later, 87 per cent of 150 trials were positive. There was little mortality-practically none after those injured in shipping had died. This indicates that the change in the chemical content of the water either did not affect the rheotactic response or that the isopods quickly became acclimated.

The animals under experimentation were placed in glass dishes which held about 1.5 liters of water. These were placed in running tap water to insure more even temperature. The stock was kept in a glass-sided room and all tests were performed in a part of this room curtained to exclude direct light. The majority of the tests were made from 8 to 12 A.M. Records were taken of the daily reactions of twenty individuals covering a period of from three to seventy-five days. This period did not include the breeding season. 


\section{RESPONSE TO CONCUSSION COMPARED WITH THE SIGN AND EFFICIENCY OF THE RHEOTACTIC REACTION}

\section{METHODS}

In testing for the sign of the rheotactic reaction in a circular current the methods described in the preceding paper ('12, p. 276) were largely used. Forceps wrapped with soft cloth were substituted for the rounded glass rod in producing the current since they are less apt to cause injuries. The isopods were stirred loose from the bottom in order to diminish the interference of positive thigmotaxis with the reaction to the water current. Not more than three animals were tested at one time and records were kept of their individual reactions.

\section{Method for determining efficiency in a circular current}

During the earlier work the sign of the response was not distinguished from the vigor of the reaction in determining the positiveness of the animals under experimentation; but it is evident that an isopod might head upstream at each trial and yet be unable to make headway against the current. Its physiological condition then would be obviously different from that of an isopod that could make rapid progress against the current although in percentage of positive responses their reactions might be identical.

In order to test the relation between the sign and the efficiency of movement, the following arbitrary standard of efficiency in the current was adopted. This represents numerically the distance covered by an isopod in a minute's reaction period:

0 no reaction

1 slight movement

2 any response between 1 and 3

3 progress one-third around the pan, positive (approximately $27 \mathrm{~cm}$.) or two-thirds, negative $(54 \mathrm{~cm}$.)

4 progress two-thirds around the pan, positive or one and one-third negative

5 progress once around the pan, positive or twice around, negative

6 any distance over 5 
In indefinite reactions the efficiency was estimated as closely as possible from the varying course taken by the isopod.

The basis upon which the relation between positive and negative reactions was worked out is shown in table 2 . In this work one isopod was used at a time. One person held the watch and recorded observations while another with the aid of a reading glass counted the number of movements of the fourth thoracic leg during a minute's reaction period and afterward measured the distance covered in that time. Distance covered per leg movement with the isopod going with the current was found to be approximately double that given when the isopod was reacting positively.

In testing for efficiency of response in a water current the rate of the current becomes of much greater importance than it is in finding the sign of the rheotactic reaction. Therefore even

TABLE 2

Showing the relation between the efficiency of movement with and against the current. Temperature 19 to $20^{\circ} \mathrm{C}$. Oxygen 5.5 to 6.5 cc. per liter

\begin{tabular}{|c|c|c|c|c|c|c|c|c|}
\hline \multicolumn{5}{|c|}{ postrive } & \multicolumn{4}{|c|}{ NEGATIYE } \\
\hline $\begin{array}{c}\text { No. } \\
\text { trials }\end{array}$ & $\begin{array}{l}\text { No. leg } \\
\text { move- } \\
\text { ments }\end{array}$ & $\begin{array}{l}\text { No. } \\
\text { centimeters } \\
\text { covered }\end{array}$ & $\begin{array}{l}\text { Ave. no. } \\
\text { centimeters } \\
\text { covered } \\
\text { per leg } \\
\text { movement }\end{array}$ & ISOPOD NOMBER & $\begin{array}{c}\text { No. } \\
\text { trials }\end{array}$ & $\left|\begin{array}{c}\text { No. leg } \\
\text { move- } \\
\text { ments }\end{array}\right|$ & $\begin{array}{c}\text { No. } \\
\text { centimeter: } \\
\text { covered }\end{array}$ & $\begin{array}{l}\text { Ave. no } \\
\text { ceat1- } \\
\text { meters } \\
\text { covered } \\
\text { per leg } \\
\text { movement }\end{array}$ \\
\hline 6 & 357 & 269 & 0.75 & VII & 10 & 367 & 455 & 1.24 \\
\hline 8 & 607 & 255.5 & 0.42 & & 8 & 560 & 593 & 1.06 \\
\hline 3 & 146 & 69 & 0.47 & & 6 & 547 & 429 & 0.78 \\
\hline \multirow[t]{2}{*}{7} & 462 & 269 & 0.58 & & 10 & 749 & 657 & 0.88 \\
\hline & & & 0.53 & $\left\{\begin{array}{l}\text { Ave. cm. per } \\
\text { leg movement }\end{array}\right\}$ & & & & 0.95 \\
\hline 9 & 642 & 175 & 0.27 & I & \multirow{5}{*}{1} & \multirow{5}{*}{35} & \multirow{5}{*}{11} & \multirow{5}{*}{0.31} \\
\hline 10 & 907 & 254 & 0.27 & VI & & & & \\
\hline 10 & 868 & 219 & 0.24 & II & & & & \\
\hline 6 & 348 & 116 & 0.33 & XI & & & & \\
\hline 10 & 775 & 397 & 0.51 & VIII & & & & \\
\hline \multirow{2}{*}{7} & 507 & 232 & 0.45 & XV & 10 & 879 & 577 & 0.65 \\
\hline & & & & & 7 & 548 & 338 & 0.61 \\
\hline 76 & 5676 & 2023.5 & 0.35 & $\left\{\begin{array}{c}\text { Totals and } \\
\text { averages }\end{array}\right.$ & 52 & 3685 & 3060 & 0.81 \\
\hline
\end{tabular}


greater care was exercised to produce a uniform rate of current in the successive trials than during the preceding experiments.

\section{Reaction to concussion}

In testing rheotaxis in a circular current there is no means of measuring the stimulus acting at any given time; consequently one is not sure that the isopod is reacting to equivalent stimuli in successive tests. This is more especially the case since the circular current has a spiral rather than a direct course. It

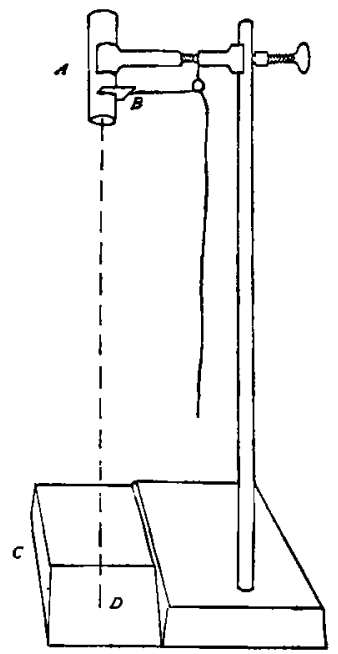

Fig. 1 Concussion apparatus.

seemed possible that an adaptation of the concussion method employed by Banta ('10, p. 453) might therefore furnish a more exact method for determining the differing physiological states.

Banta dropped a steel or lead ball to a pine board upon which the isopod to be tested was placed in a wax bottomed Stender dish. He does not speak of precautions to prevent the ball from rebounding, and presumably none were taken. Of course the vigor and number of the rebounds would vary partially as the distance through which the ball was dropped; but when this rebound is present the animals may and probably do react to the succession of smaller shocks after being aroused by the 
initial shock. This might happen although no reaction was given to the initial stimulus.

In order to eliminate these rebounds, the apparatus was devised as shown in figure. 1. A short cylinder $A$ was fastened directly above the slanted portion of the steel block $C$. The steel ball to be dropped rested upon a cardboard $B$ which worked in a slot in the cylinder. This was arranged $50 \mathrm{~cm}$. above the point of concussion $D$ on the block $C$. The block $C$ is made of forged steel $10 \mathrm{~cm}$. wide, $2.5 \mathrm{~cm}$. high, and $20 \mathrm{~cm}$. in greatest length. The upper surface is $15 \mathrm{~cm}$. long. The sloping part measured $5.6 \times 10 \mathrm{~cm}$. and was machined to give a true surface. The slope is such that the falling ball rebounds at an angle and thus strikes the block but once. A steel ball weighing 11.927 grams was found to furnish the most satisfactory stimulus when dropped $50 \mathrm{~cm}$. At the moment of striking the block, this had a momentum of 3734 C. G. S. units.

The isopod to be tested was confined in a petri dish $3 \mathrm{~cm}$. in diameter, placed on the level surface $5 \mathrm{~cm}$. from the point of impact. The isopod was allowed to stand five minutes to recover from the shock of handling. Then the responses were taken to twenty successive concussions. A reading glass was used in order to make out slight movements. After each individual trial the isopod was allowed to come to rest if a response had occurred. In all cases the reactions were taken for the first twenty trials and the lack of a reaction was considered to be quite as significant as a definite movement. Whenever the animal showed a tendency to crawl without the action of an external stimulus, it was allowed to come to rest before further trials were made. With practice the response to shock could be readily distinguished from movement due to other causes.

Numbers with the following values (cf. Banta '10, p. 453) were used to record the strength of the reactions:

0 no reaction

1 movement of antennae or slight movement of other appendages

2 extended movement of the antennae or strong enough movement of the legs to result in a slight stirring of the body 
3 decided movement of the anterior end of the body or crawling one or two steps

4 more extended crawling covering about a centimeter

5 crawling over a centimeter

6 a definite jump followed by rapid running

The use of these numbers in recording the reactions is illustrated in table 3.

Banta records a mixed type of response. In number four of his classes of reaction he states that the isopod moved antennae or other appendages or bent the anterior end of the body and followed this by crawling. Reactions of this kind were not given under the conditions of my experiment and may have been due to the repeated rebounds acting as a cumulative stimulus. Concussion occurring while the animal was crawling usually caused a cessation of action. Often when the isopod was quiet the only reaction given was a settling of the body.

Table 3 shows some tests for one isopod made on successive days. The test recorded in column 7 was made immediately after that in column 6 but with a ball weighing only two grams and hence it developed a momentum of only 626 C. G. S. units. This appears to be near the threshold of stimulation when the isopod is as free as possible from thigmotactic interference.

The tests recorded in columns 5 and 9 immediately followed those given in columns 4 and 8 respectively. The difference was that in the first series of trials the isopods were resting more or less closely in the angle at the edge of the dish, while in the second they had been stimulated until they came to rest free from the edge. In column 5 there is some evidence that part of the increased response was due to this recent mechanical stimulation. By comparing these reactions it becomes apparent that the position of the isopod with reference to the angles of the container may affect their response to a shock stimulus. The position of the isopod in the containers used cannot be readily controlled by the experimenter without increased mechanical stimulation. Suitable dishes with hemispherical inner surfaces were not obtainable when these experiments were performed. Since the error from this cause is the same for normal 
TABLE 3

Reactions of isopod no. II to shock stimulus of $\$ 7 \$ 4$ C. G. S. units on successive days

\begin{tabular}{|c|c|c|c|c|c|c|c|c|c|}
\hline & 1 & 2 & 3 & 4 & 5 & 6 & 72 & 8 & 9 \\
\hline $\begin{array}{c}\text { Oxygen in cubic } \\
\text { centimeters per } \\
\text { liter......... }\end{array}$ & 7.0 & 7.0 & 6.5 & 6.5 & 6.3 & 6.3 & 7.0 & 7.0 & 7.0 \\
\hline Temperature.... & 15 & 16 & 17 & 20 & 20 & 16 & 16 & 16 & 16 \\
\hline $\begin{array}{l}\text { Position in Petri } \\
\text { dish.......... }\end{array}$ & free & free & free & $\begin{array}{l}\text { loosely } \\
\text { in angle }\end{array}$ & free & free & free & $\begin{array}{l}\text { closely } \\
\text { in angle }\end{array}$ & free \\
\hline Reactions........ & $\begin{array}{l}3 \\
0 \\
1 \\
0 \\
1 \\
0 \\
0 \\
0 \\
0 \\
0 \\
4 \\
0 \\
1 \\
1 \\
1 \\
2 \\
3 \\
4 \\
1 \\
1\end{array}$ & $\begin{array}{l}4 \\
1 \\
1 \\
2 \\
0 \\
1 \\
1 \\
1 \\
2 \\
1 \\
3 \\
1 \\
3 \\
2 \\
2 \\
1 \\
1 \\
1 \\
0 \\
0\end{array}$ & $\begin{array}{l}2 \\
2 \\
2 \\
2 \\
6 \\
2 \\
1 \\
2 \\
2 \\
2 \\
1 \\
2 \\
2 \\
1 \\
1 \\
1 \\
1 \\
1 \\
1 \\
0\end{array}$ & $\begin{array}{l}1 \\
1 \\
1 \\
1 \\
1 \\
1 \\
1 \\
1 \\
1 \\
1 \\
1 \\
1 \\
1 \\
1 \\
1 \\
1 \\
1 \\
2 \\
1 \\
0\end{array}$ & $\begin{array}{l}2 \\
1 \\
1 \\
0 \\
3 \\
3 \\
1 \\
5 \\
1 \\
2 \\
0 \\
1 \\
3 \\
2 \\
2 \\
1 \\
1 \\
1 \\
1 \\
1\end{array}$ & $\begin{array}{l}2 \\
1 \\
0 \\
1 \\
2 \\
3 \\
1 \\
1 \\
4 \\
1 \\
2 \\
2 \\
3 \\
1 \\
2 \\
1 \\
5 \\
1 \\
1 \\
1\end{array}$ & $\begin{array}{l}0 \\
0 \\
0 \\
0 \\
0 \\
0 \\
1 \\
0 \\
0 \\
0 \\
0 \\
0 \\
0 \\
0 \\
0 \\
0 \\
0 \\
0 \\
0 \\
0\end{array}$ & $\begin{array}{l}1 \\
0 \\
1 \\
1 \\
1 \\
1 \\
1 \\
1 \\
1 \\
1 \\
1 \\
1 \\
1 \\
0 \\
1 \\
1 \\
1 \\
1 \\
0 \\
1\end{array}$ & $\begin{array}{l}1 \\
4 \\
4 \\
1 \\
5 \\
0 \\
3 \\
0 \\
1 \\
1 \\
1 \\
0 \\
2 \\
1 \\
0 \\
2 \\
1 \\
4 \\
2 \\
4\end{array}$ \\
\hline Sum............ & 23 & 28 & 33 & 20 & 32 & 35 & 1 & 17 & 37 \\
\hline $\begin{array}{c}\text { Number responses } \\
\text { other than zero.. }\end{array}$ & 12 & 17 & 19 & 19 & 18 & 19 & 1 & 17 & 17 \\
\hline $\begin{array}{l}\text { Average vigor } \\
A=\frac{\text { sum }}{\text { no. of trials }} \\
B=\frac{\text { sum }}{\text { no. movements }}\end{array}$ & $\begin{array}{l}1.15 \\
1.9\end{array}$ & $\begin{array}{l}1.4 \\
1.6\end{array}$ & $\begin{array}{l}1.65 \\
1.73\end{array}$ & $\begin{array}{l}1.0 \\
1.05\end{array}$ & $\begin{array}{l}1.6 \\
1.77\end{array}$ & $\begin{array}{l}1.75 \\
1.84\end{array}$ & $\begin{array}{l}0.5 \\
1.0\end{array}$ & $\begin{array}{l}0.85 \\
1.0\end{array}$ & $\begin{array}{l}1.85 \\
2.18\end{array}$ \\
\hline $\begin{array}{l}\text { Per cent positive } \\
\text { rheotaxis........ }\end{array}$ & 90 & 80 & 90 & 100 & & 80 & & 90 & \\
\hline Efficiency... & 3.4 & 3.4 & 3.5 & $\mathbf{3 . 3}$ & & 2.8 & & 2.6 & \\
\hline
\end{tabular}

1 Except column 7.

22 gram ball falling $50 \mathrm{~cm}$. gives a momentum of $626 \mathrm{C}$. G. S. units. 
and depressed animals and since all were tested under uniform conditions, this source of error is probably not vital as far as the larger variations in physiological condition are concerned.

Two average vigors of response are given in table 3 . The first (A) is based on the principle that an animal may respond to a given stimulus by remaining quiescent, when its reaction must be expressed numerically as zero; that this reaction is as significant as when the most violent movement occurs and should be included in a scheme of averages. The second (B) follows the reasoning that only movements should be counted as reactions. This system was followed by Banta in his work with concussion. The fallacy of the reasoning may be seen by comparing the reactions listed in columns 4, 7 and 8 . According to the second system of averaging all these would be considered as equivalent while a glance at the responses in detail shows that this is not the case. Consequently the first method has been taken in this work to summarize the reactions into one significant figure.

INTERRELATIONS BETWEEN RESPONSE TO UNIFORM CONCUSSIONS AND THE SIGN AND EFFICIENCY OF RHEOTAXIS

As the percentage of positive rheotactic responses varied from day to day, did the efficiency of movement and the reaction to shock vary in like or opposite manner? If all are the direct expression of the physiological state of the animal the variations should be similar and a decrease in positiveness should be accompanied by a decrease in efficiency and in the vigor of the concussion reaction.

The relation or non-relation between these factors is shown in charts 1-6 (pp. 275-282). These show that in the main the larger variations in efficiency and positiveness are in agreement although this differs somewhat with individuals, notably with isopod no. XIV, chart 6 . The larger concussion variations show little agreement with the other factors although there are some cases of notable disagreement which will be discussed later (p. 273). 
The minor daily variations of the number of positive reactions and the efficiency of the rheotactic response run more closely parallel with each other than either does with the variations in the reactions to shock. The shock variation and the variation in positiveness oppose each other almost as often as they agree. The reaction to shock and efficiency are a trifle more uniform in their variation but not enough so to warrant any claim of agreement. It is probably significant that in all cases the agreement is more pronounced when the vigor of reactions decreases than under other conditions.

There is another way of determining the relation between these different factors: one may compare the concussion responses and efficiency accompanying a state of high positiveness with those found with a low percentage of positive responses. The results of such a comparison are shown in table 4 .

In this table the efficiency and shock reactions which were given by animals showing a positive response of 80 per cent or over are compared with those accompanying 40 per cent or less of positive rheotactic reactions. The table shows that in every case the high percentage of positiveness is accompanied by a high degree of efficiency in the current. In the main a low efficiency accompanied a low positive reaction; but this was not always true, notably in isopods nos. VII, XII and XIX. These isopods gave more negative responses to the current than positive and showed as high efficiency when negative as when they were positive. However, the average shows almost as marked a difference in the efficiency as in the positiveness.

Again, there is no relationship between the reaction to shock and the positiveness of the isopods. It is evident from the table that while low vigor of reaction to shock may accompany a similar status of the rheotactic factors such is not necessarily true. The case of isopod no. I is significant. This animal gave much more vigorous shock reactions when giving a low positive and low vigor response than under the reverse conditions (see also p. 272). The average of all the responses is practically the same regardless of whether given with high or low rheotactic positiveness. 
TABLE 4

Showing the efficiency and response to shock accompanying high and low positiveness. The responses are averages of all the reactions given by the individual under the conditions of the table. The general averages are obtained by multiplying the number of instances by the average response and dividing by the total number of instances.

\begin{tabular}{|c|c|c|c|c|c|c|c|c|c|c|c|c|}
\hline \multicolumn{6}{|c|}{$\begin{array}{l}\text { RHEOTAXTS } 80 \text { PER CENT, OR ABOVI } \\
\text { POBITIVI }\end{array}$} & \multirow[b]{2}{*}{ LOOPOD NUMBER } & \multicolumn{6}{|c|}{$\begin{array}{l}\text { RHMOTAXTA } 40 \text { PER CWNY, OR BELOW } \\
\text { POBMTIVE }\end{array}$} \\
\hline 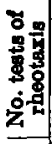 & & 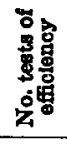 & 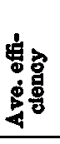 &  & 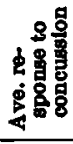 & &  & $\mid$ & 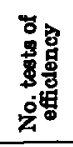 &  &  & 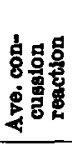 \\
\hline 38 & 91 & 36 & 2.8 & 24 & 0.86 & I & 12 & 25 & 12 & 1.7 & 12 & 1.40 \\
\hline 33 & 93 & 33 & 2.9 & 22 & 1.60 & II & 12 & 12 & 12 & 1.4 & 12 & 1.36 \\
\hline 19 & 94. & 17 & 2.5 & 4 & 1.40 & III & & 0 & 5 & 0.0 & $\mathbf{5}$ & 1.04 \\
\hline 36 & 94 & 35 & 2.8 & 20 & 1.12 & IV & & 35 & 2 & 3.2 & & \\
\hline 2 & 90 & 1 & 2.1 & & & V & 12 & 26 & 12 & 1.8 & 2 & 0.45 \\
\hline 35 & 93 & 35 & 2.7 & 4 & 1.38 & VI & 5 & 8 & 5 & 1.7 & 4 & 0.50 \\
\hline 11 & 90 & 11 & 2.7 & 8 & 1.40 & VII & 26 & 19 & 26 & 2.9 & 11 & 1.30 \\
\hline 29 & 96 & 29 & 2.8 & 11 & 1.40 & VIII & 1 & 40 & 1 & 2.7 & & \\
\hline 21 & 91 & 21 & 2.9 & 8 & 0.96 & IX & & 17 & 6 & 3.6 & & \\
\hline 6 & 81 & 6 & 2.8 & & & $\mathbf{x}$ & 1 & 0 & 1 & 0.0 & & \\
\hline 32 & 90 & 32 & 2.9 & 14 & 1.13 & XI & & 23 & 9 & 1.5 & $\mathbf{5}$ & 0.79 \\
\hline 8 & 84 & 8 & 2.5 & 5 & 0.56 & XII & 16 & 24 & 16 & 2.5 & $\mathbf{3}$ & 1.13 \\
\hline 10 & 86 & 10 & 2.7 & 1 & 0.40 & XIII & & 28 & 5 & 1.7 & 2 & 0.63 \\
\hline 32 & 93 & 32 & 2.6 & 21 & 0.99 & XIV & & & & & & \\
\hline 10 & 82 & 10 & 2.4 & $\mathbf{5}$ & 0.66 & $\mathbf{X V}$ & 12 & 22 & 12 & 2.2 & 8 & 0.74 \\
\hline 9 & 91 . & 9 & 2.7 & 8 & 0.70 & XVI & & 0 & 3 & 1.5 & 3 & 0.20 \\
\hline & & & & & & XVII & & 37 & 3 & 2.6 & 2 & 1.45 \\
\hline 7 & 84 & 7 & 2.6 & 5 & 1.31 & XVIII & & 27 & 3 & 2.2 & 1 & 1.10 \\
\hline 1 & 90 & 1 & 2.7 & 1 & 1.50 & XIX & 10 & 20 & 10 & 2.9 & 8 & 1.62 \\
\hline 4 & 87 & 4 & 2.5 & 3 & 1.12 & $\mathbf{X X}$ & 3 & 14 & 3 & 2.3 & 3 & 0.72 \\
\hline 363 & 91 & 357 & 2.7 & 165 & 1.03 & $\left\{\begin{array}{r}\text { Total and } \\
\text { averages }\end{array}\right\}$ & 134 & 21 & 134 & 2.2 & 81 & 1.04 \\
\hline
\end{tabular}

Table 5 shows a similar state of affairs when the responses accompanying high and low efficiency are compared. An effciency of 2.8 or more is regarded as high and one of 1.8 or less as low. As before isopods nos. VII, XII, XV and XIX, which showed a large number of negative responses, indicate that high efficiency and a high degree of positiveness do not necessarily go together. On the other hand, the individual items and averages indicate that in the main they do. In stream isopods, how- 
ever, low efficiency is always accompanied by low positiveness. Again the averages show almost as striking differences as when the positiveness of the response was taken as a basis of comparison in table 4.

The accompanying reactions to concussion indicate that a high vigor of shock response may occur with either a high or low rate of efficiency and vice versa. Again the averages of concussion responses are practically identical and show no apparent relation to efficiency.

TABLE 6

Showing the rheotactic and shock reactions accompanying high and low efficiency. The data were oblained as in table 7

\begin{tabular}{|c|c|c|c|c|c|c|c|c|c|c|c|c|}
\hline \multicolumn{6}{|c|}{ merrexcr 2.8 on Lsovy } & \multirow[b]{2}{*}{ HOPOD NUYMIR } & \multicolumn{6}{|c|}{ Impranser 1.8 on Lres } \\
\hline  & 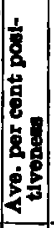 & 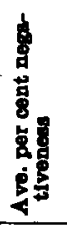 & 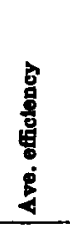 & 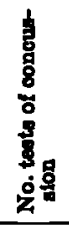 & 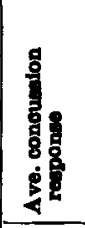 & &  & & 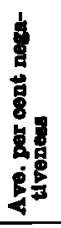 & 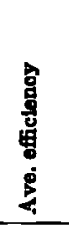 & 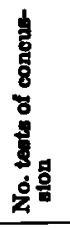 & 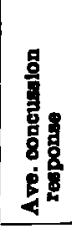 \\
\hline 18 & 89 & 2 & 3.1 & 11 & 0.90 & I & & 28 & 8 & 1.5 & 9 & 1.43 \\
\hline 18 & 89 & 6 & 3.1 & 12 & 1.64 & II & 10 & 18 & 3 & 1.6 & 10 & 1.16 \\
\hline $\mathbf{5}$ & 92 & 4 & 2.9 & 1 & 1.20 & III & 6 & 8 & 2 & 0.3 & 5 & 1.04 \\
\hline 33 & 80 & 13 & 3.1 & 15 & 1.15 & IV & & & & & & \\
\hline & & & & & & V & & 21 & 11 & 1.5 & 2 & 1.00 \\
\hline 19 & 91 & 7 & 3.2 & 7 & 1.50 & VI & 3 & 23 & 0 & 0.9 & 3 & 0.95 \\
\hline 25 & 36 & 56 & 3.2 & 7 & 1.22 & VII & 2 & 5 & 5 & 1.0 & 2 & 1.00 \\
\hline 14 & 96 & 1 & 3.0 & 4 & 1.54 & VIII & & & & & & \\
\hline 21 & 81 & 8 & 3.1 & 6 & 1.08 & IX & & & & & & \\
\hline 4 & 83 & 13 & 3.0 & & & $\mathbf{X}$ & & & & & & \\
\hline 18 & 86 & 8 & 3.1 & 10 & 1.39 & $\mathbf{X I}$ & 3 . & 7 & 0 & 0.7 & 3 & 0.00 \\
\hline 10 & 53 & 43 & 2.9 & 5 & 0.84 & XII & & & & & & \\
\hline 6 & 80 & 0 & 3.1 & & & XIII & & 23 & 3 & 0.9 & & \\
\hline 14 & 89 & 5 & 3.1 & 7 & 1.00 & XIV & & & & & & \\
\hline 12 & 51 & 41 & 3.0 & 6 & 1.20 & $\mathbf{X V}$ & & & & & & \\
\hline 4 & 90 & 3 & 3.0 & 3 & 0.57 & XVI & 2 & 0 & 5 & 1.3 & 2 & 0.25 \\
\hline 2 & 40 & $\mathbf{5 0}$ & 2.8 & 1 & 1.45 & XVII' & & & & & & \\
\hline 3 & 74. & 26 & 2.8 & 2 & 0.70 & XVIII & & & & & & \\
\hline 15 & 39 & 48 & 3.0 & 13 & 1.40 & XIX & & & & & & \\
\hline 3 & 60 & 37 & 3.1 & 2 & 1.07 & $\mathbf{X X}$ & 1 & 40 & 40 & 1.5 & 1 & 0.95 \\
\hline 234 & 74 & 15 & 3.1 & 112 & 1.22 & $\left\{\begin{array}{c}\text { Totals and } \\
\text { averages }\end{array}\right\}$ & 46 & $17 \mid$ & 6 & 1.2 & $\mathbf{3 0}$ & 1.26 \\
\hline
\end{tabular}

1 Tested only during malting period. 
Table 6 shows the relation between the negative and indefinite rheotactic responses with the rate of efficiency and with shock reactions. Part I gives the data taken when the negative responses were 60 per cent or more of the total reaction. Under these conditions the percentage of positive responses is low but both the efficiency rate and the concussion responses are high. The second part of the table shows the responses when over 60 per cent of the total reactions were indefinite. Here again the positive reactions are necessarily few. But it will be noted that the rate of efficiency is low, much lower than when low positiveness was taken as the basis of comparison. The concussion response is almost the same as was shown to accompany high and low positiveness and high and low efficiency.

TABLE 6

Showing the responses accompanying high negative and high indefinite rheotactic response

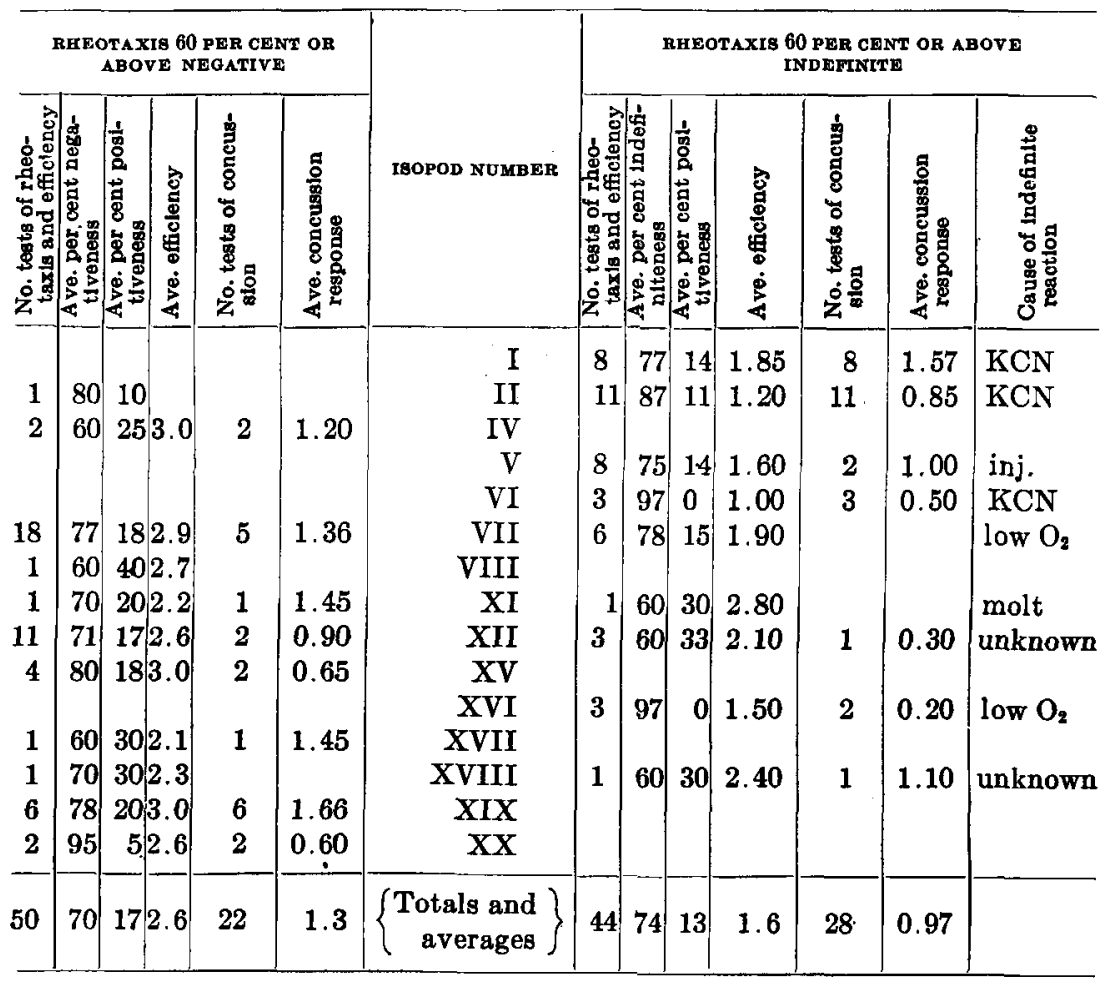


The responses accompanying low negativeness and low indefiniteness may be seen in the first parts of table 4 . Of necessity where either response is above 60 per cent of the total number of reactions the other two must be low. From table 6 it is evident that a high percentage of negative reactions may accompany a high rate of efficiency. But this condition was found only fifty times in the course of these experiments while the opposite response of high positiveness and high efficiency occurred 357 times as shown in table 4. For these 357 times the positive responses averaged 91 per cent, and the negative ones 4 per cent of the total response. From this it follows that under natural conditions the negative response does not vary with the efficiency or vigor of movement as does the positive response. The relationship may be stated as follows:

The rate of positiveness is usually high when the efficiency is high and is always low when the efficiency is low. Normally the negative response is low in the stream mores. It is always low when the efficiency is very low and is usually low when the efficiency is high. However it is never high unless the efficiency is fairly high and in this alone it agrees with the positive reaction.

On the other hand the indefinite response is rarely given with high efficiency and is usually given when the rate of efficiency is low. It is not high in stream isopods under normal conditions but always occurs when the metabolic rate of the isopod has been experimentally decreased.

From the data presented so far the response to shock has apparently no direct relation to any of the other factors. When the positiveness and efficiency of the rheotactic reactions that accompany concussion responses with a vigor of 1.2 or more are compared with those accompanying 0.8 or less, the following average results were obtained: 160 trials with the shock reaction 1.2 or more averaged 1.52. The average positive response was 71 per cent and the average efficiency, 2.6. Ninety-four trials with the shock response 0.8 or less averaged 0.46 . The accompanying rheotactic reactions averaged 59 per cent with an average efficiency of 2.1. Eight of the twenty isopods gave as strong or 
stronger positive rheotactic reaction with a low as with a high vigor of shock reaction. This gives some indication of relationship between the shock and rheotactic reactions but the evidence is too slight to warrant the conclusion that such a relationship exists, particularly in the face of the conflicting evidence given in other instances when this possible relationship has been considered. ${ }^{2}$

\section{DAILY VARIATIONS IN THE RHEOTACTIC REACTION}

In my earlier work on rheotaxis with groups of isopods ('12, p. 340) irregularities were observed in the reactions of different members of a group kept under constant experimental conditions. It was also found (p. 277) that the reaction of a group of eight highly positive isopods varied from day to day. From these observations the question arose as to the difference in the rheotactic response of the individual isopods and the degree of daily variation of this response when kept under similar experimental conditions. In other words, to what extent is the internal mechanism of different isopods from the same habitat unlike and how great a variation of this internal mechanism takes place automatically from day to day?

In testing for these points isopods selected at random were isolated in glass jars in a liter of water which was changed daily. ' University of Illinois tap water saturated with oxygen at

${ }^{2}$ Experiments on a different phase of this subject performed since the above was written, incidentally confirm these results. 150 isopods were tested for from one to twenty-five days with the following results:

\begin{tabular}{|c|c|c|c|c|c|c|c|}
\hline \multirow[t]{2}{*}{ NO. TRIALS } & \multicolumn{4}{|c|}{ RHEOTACTIC REBPONBE } & \multirow[t]{2}{*}{ EFFICIENCY } & \multirow{2}{*}{$\begin{array}{l}\text { NO. cONcussion } \\
\text { TRIALS }\end{array}$} & $\begin{array}{l}\text { AVE. VIGOR OF } \\
\text { CONCUBSION REBPONBS }\end{array}$ \\
\hline & + & $\overline{-}$ & $\alpha$ & 0. & & & 122 \\
\hline 140 & 16 & 49 & 23 & 12 & 2.06 & $\begin{array}{r}76 \\
76\end{array}$ & 1.14 \\
\hline 69 & 11 & 81 & 8 & & 2.65 & 37 & 0.95 \\
\hline 22 & 12 & 5 & 75 & 8 & 1.6 & 14 & 1.03 \\
\hline
\end{tabular}

These later concussion tests were made with the isopods in a hemispherical container and show but little more correlation with the rheotactic factors than did the response in petri dishes.

THE JOURNAL OF RXPERIMANTAL ZOZLOGT, YOL. 15 , No. 3 
atmospheric pressure was used throughout. The vessels were placed in running water to keep the temperature more uniform. During the period of experimentation which lasted seventy-five days the temperature ranged from 15 to $22^{\circ}$. These variations in temperature usually took place slowly and according to previous experiments ('12, pp. 316, 326) probably did not affect the rheotactic response and certainly cannot be held to account for all the variations.

The oxygen varied from 5.5 to $7.0 \mathrm{cc}$. per liter but this does not affect the rheotactic reaction (Allee '12, p. 281). The amount of carbon dioxide present was practically constant. Food was furnished by placing a few green leaves of Elodea with each isopod; these were renewed often. The records of these tests are shown in charts 1 to $6 \mathrm{pp}$. 275-282.

Molting was found to be responsible for part of the variation, but there was some variation other than that caused by the molting period in the response of the most uniformly positive isopods. Thus isopod no. I, chart 1 , gave a normal positive response of 88 per cent of the total number of trials and yet repeated the response of the preceding day only 14 times in 60 trials. Isopod no. II, chart 2, with an average positive response of 86 per cent repeated the preceding reaction 16 times in 53 trials. Isopod no. VIII, chart 4, with an average of 90 per cent positive reac-

Chart 1 The rheotactic and concussion responses of isopod no. I.

Chart 2 The rheotactic and concussion responses of isopod no. II.

In the graphs the abscissae represent time; the ordinates give the response. In all instances unless otherwise mentioned the intervals marked on the base line indicate days. The solid line gives the positive rheotactic responses of the isopods expressed in per cent of the total number of trials. The slightly broken line shows the efficiency of the rheotactic movement, while the dotted line gives the concussion reactions. In each case the straight line shows the average response given by the individual under consideration under normal conditions. In the plotting the scale for the percentage of positive responses is one-twentieth of that for either of the other responses. The letters on the charts have the following meanings: M.a., molted anterior part; M.p., molted posterior part; $M$., molted whole covering; $K C N$, put in potassium cyanide; Normal water, changed from potassium cyanide to the water normally used; Low oxygen, put in water having an oxygen content of 0.5 to $1.0 \mathrm{cc}$. per liter; High oxygen, returned to the water normally used $\left(\mathrm{O}_{2} 5.5\right.$ to $7.0 \mathrm{cc}$. per liter $)$. 


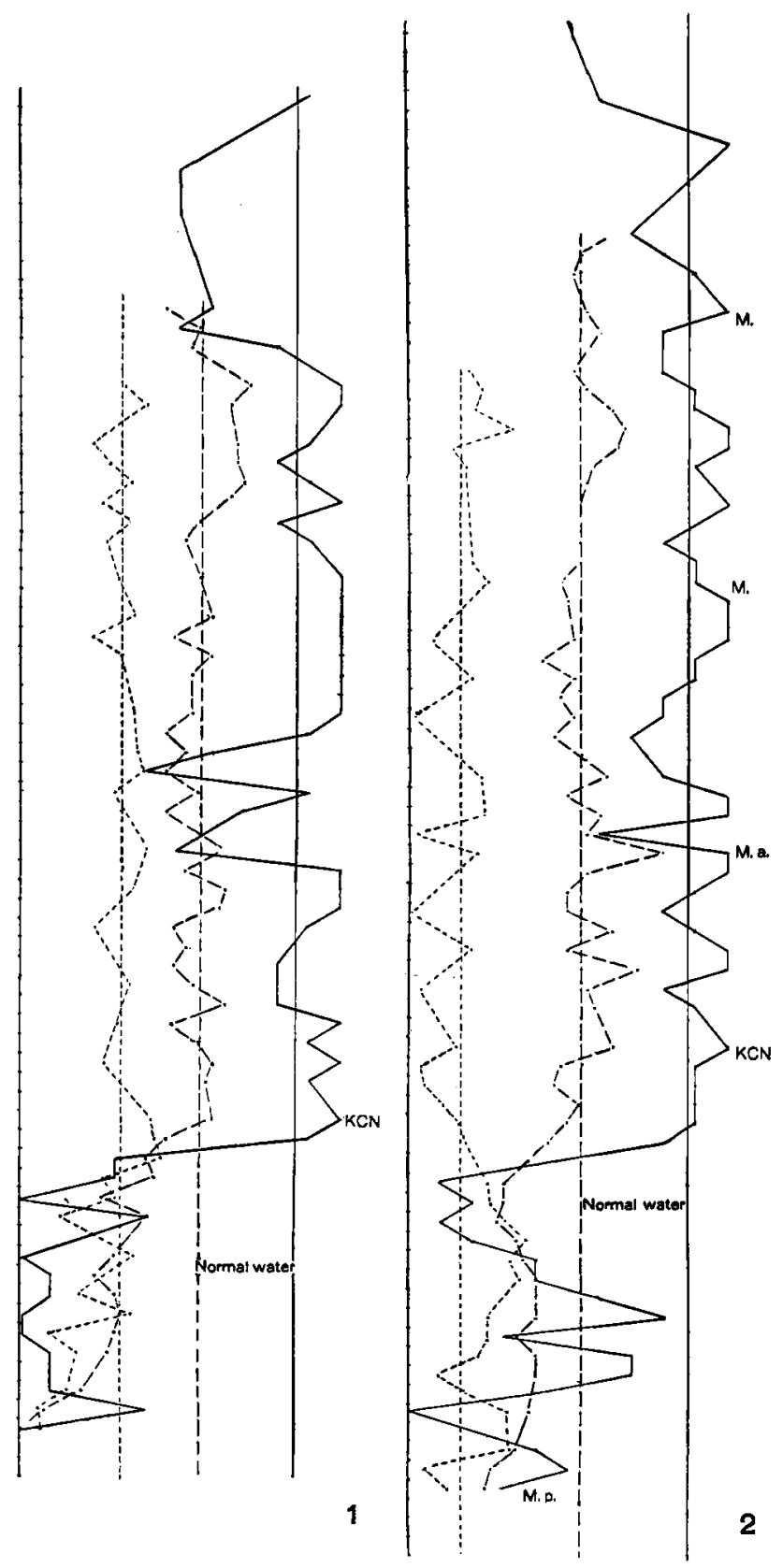


tions gave identical responses 11 times in 33 trials. These are typical of the responses of the highly positive isopods.

Some of the isopods show greater variation, typically represented by no. VII. This isopod had as strong tendency to give negative as positive reactions (table 7 ). The positive response varied greatly from day to day often without a corresponding variation in the efficiency of the reaction, although this latter item varied more than in the more uniformly positive isopods cited above.

Attention should be called to the facts illustrated in table 7 . This table shows that those stream isopods which naturally give a low percentage of positive responses give a higher percentage of negative than of indefinite reactions. That is, if a stream isopod does not go positive to the current under normal conditions it has a distinct tendency to go more negative than indefinite. Exactly the reverse is true of pond isopods. ${ }^{3}$

Another state of affairs is illustrated by the reactions of isopod no. $\mathrm{V}$, table 7. This individual was injured in handling on the sixth day of observation. Trials were continued until its death 28 days later. In this case, however, although the positive response shows the decided cut that would be expected, the indefinite, not the negative response increased. Under these conditions the efficiency was also markedly decreased, bearing out the experimental results of a high degree of indefiniteness accompanying low efficiency in stream isopods, however the low efficiency be induced.

The cases of the isopods (nos. VII, XII, XV and XIX) that gave an unusually high negative response for the stream mores have been discussed at some length (p. 272) and will be summed up later (p. 280). In general the table shows that there is a relation between the positiveness of the rheotactic reaction and the rate of efficiency and there is slight evidence of a relationship between these two rheotactic factors and the concussion response.

3 Of 827 trials of normal pond isopods ('12, table 6, p. 290) 29 per cent of the reactions were positive, 30 per cent were negative and 41 per cent were indefinite. This shows the high percentage of indefiniteness in the typical rheotactic reaction of pond isopods. 


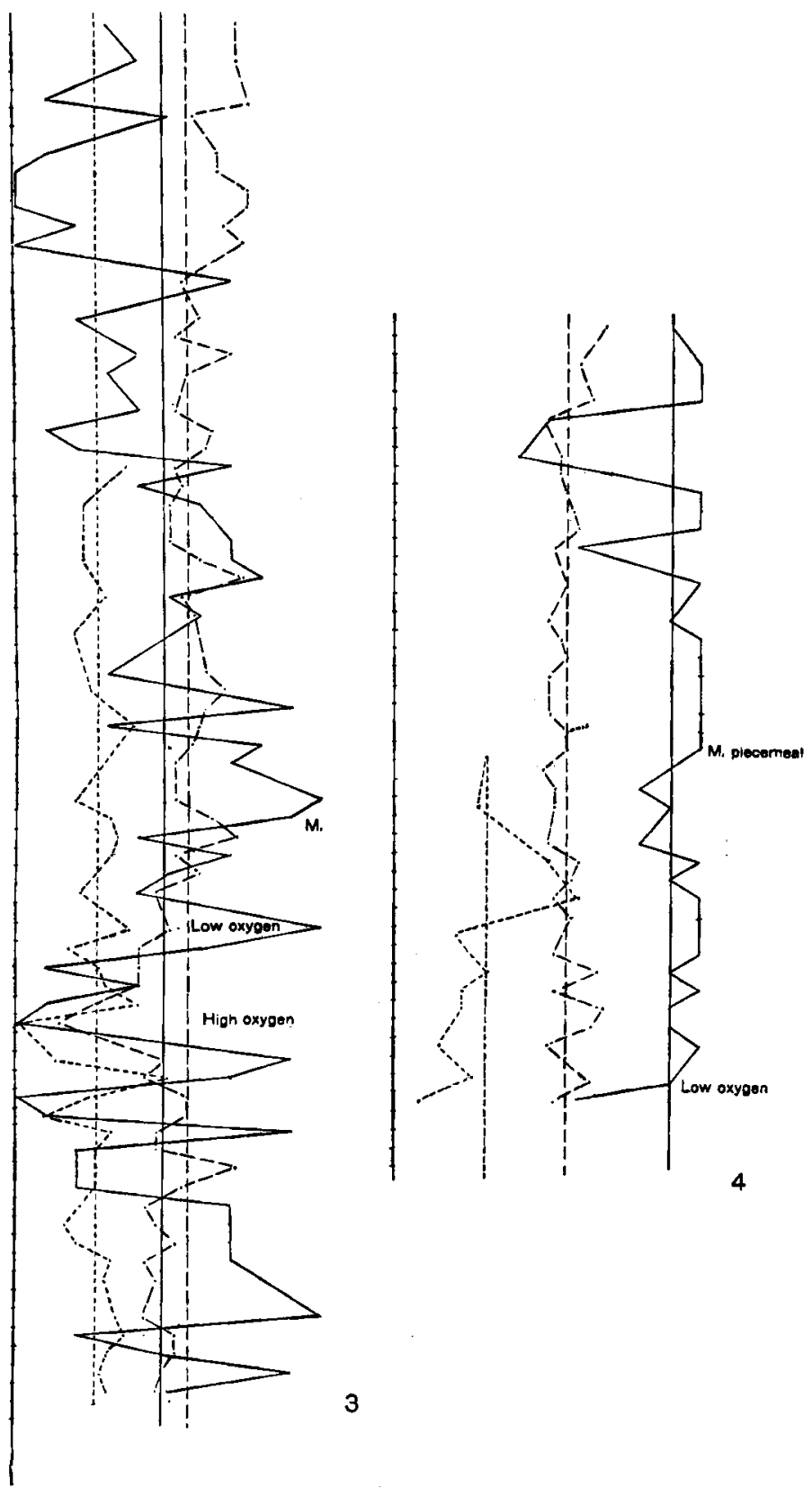

Chart 3 The rheotactic and concussion responses of isopod no. VII. For details of charting, see chart 1, p. 274 .

Chart 4 The rheotactic and concussion responses of isopod no. VIII. For methods of plotting, see chart 1, p. 274. 
TABLE 7

Showing the average reactions of the individual isopods under identical conditions. The data were compiled from the successive reactions of isopods before they were subjected to changes in the environment. Thus isopod no. I was tested 99 times under such conditions making a total of $\$ 90$ individual trials. Of these 88 per cent were positive, $\$$ per cent negative and 9 per cent indefinite. The efficiency was recorded 36 times and averaged 2.83. The average vigor of 19 concussion trials ( 380 individual tests) was 0.86 . The final averages were obtained by multiplying the significant figures by the number of trials of which they are averages and dividing by the total number of trials

\begin{tabular}{|c|c|c|c|c|c|c|c|c|}
\hline ISOPOD NUMBER & 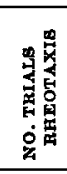 & 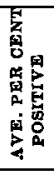 & 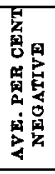 & 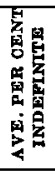 & 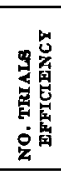 & 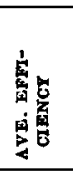 & 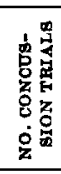 & 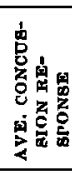 \\
\hline I & 39 & 88 & 3 & 9 & 36 & 2.83 & 19 & 0.86 \\
\hline II & 32 & 86 & 10 & 4 & 28 & 2.83 & 23 & 1.61 \\
\hline III & 23 & 87 & 3 & 10 & 20 & 2.45 & 6 & 1.39 \\
\hline IV & 52 & 82 & 11 & 7 & 49 & 2.86 & 18 & 1.26 \\
\hline V & 21 & 44 & 14 & 42 & 19 & 1.82 & 5 & 0.80 \\
\hline VI & 35 & 87 & 6 & 7 & 35 & 2.86 & 7 & 1.50 \\
\hline VII & 56 & 49 & 41 & 10 & 56 & 2.85 & 35 & 1.35 \\
\hline VIII & 34 & 90 & 6 & 4 & 34 & 2.80 & 10 & 1.50 \\
\hline IX & 39 & 72 & 12 & 16 & 39 & 3.00 & 14 & 1.03 \\
\hline $\mathrm{X}$ & 7 & 83 & 7 & 10 & & & & \\
\hline XI & 32 & 76 & 17 & 7 & 32 & 2.80 & 10 & 1.39 \\
\hline XII & 33 & 48 & 41 & 11 & 33 & 2.50 & 10 & 0.83 \\
\hline XIII & 26 & 67 & 7 & 26 & 26 & 2.50 & 6 & 0.12 \\
\hline XIV & 38 & 88 & 6 & 6 & 38 & 2.60 & 26 & 0.97 \\
\hline$X V$ & 42 & 56 & 32 & 12 & 42 & 2.57 & 32 & 0.68 \\
\hline XVI & 6 & 92 & 3 & 5 & 6 & 2.80 & 5 & 0.96 \\
\hline XVIII & 16 & 62 & 27 & 11 & 16 & 2.46 & 9 & 1.16 \\
\hline $\mathrm{XIX}$ & 23 & 44 & 44 & 12 & 23 & 2.86 & 20 & 1.30 \\
\hline$\dot{x} x$ & 9 & 59 & 35 & 6 & 9 & 2.40 & 7 & 1.00 \\
\hline $\begin{array}{l}\text { Totals and } \\
\text { averages. }\end{array}$ & 563 & 71 & 18 & 11 & 548 & 2.74 & 362 & 1.07 \\
\hline
\end{tabular}

\section{THE QUESTION OF A DAILY RHYTHM}

One other problem in the variation in response remains to be mentioned. That is the question of a daily rhythm in the rheotactic reaction such as Bohn found to exist in Convoluta (Bohn '03, '03 a). A large number of tests have been made throughout the entire period of experimentation covering the time from 
7 A.M. to midnight without any evidence of such a variation. Thus the tests upon which this paper is based were made largely from 8 A.M. to 12 noon. Those recorded in the preceding publication ('12) were made largely in the afternoon and evening up to midnight, although some tests were made in the early morning. This leaves the interval from midnight till 7 A.M. untested.

In order to find if there was evidence of a daily rhythm three uniformly positive isopods (nos. I, II and VI) were tested every hour for twenty-four hours. The results are shown in chart 7, p. 283. The reaction of isopod no. $I$ is not given since it does not differ essentially from that of no. II. There is no evidence of a daily rhythm. The decrease in the positiveness of the reaction of no. VI towards the end of the period is due to fatigue as is shown by the fact that it was three days before the isopod recovered its normal positiveness. Since there was no evidence here of a daily periodicity of reaction and since the earlier data all point against the existence of such a daily rhythm, no further tests were made along this line.

\section{EFFECT OF LOW OXYGEN AND POTASSIUM CYANIDE ON THE REACTIONS OF INDIVIDUAL ISOPODS}

It has been shown that both potassium cyanide and low oxygen decrease the positiveness of stream isopods ('12, pp. 298 and 314). Experiments were run to determine the effect of these conditions upon the reactions of individuals, especially as regards the efficiency of the rheotactic response and the vigor of the concussion reaction. Typical effects of potassium cyanide may be seen in charts 1 and 2 (p. 275) of low oxygen in charts 3,4 and 5, pp. 277-281.

Both the positiveness and the vigor of the reaction to current were diminished, though from one to five days might elapse before the reaction was greatly affected. The length of this period differed with different isopods. On the other hand, the response to concussion at first increased (charts 1,2,3 and 5)

\footnotetext{
${ }^{4}$ Potassium cyanide, $\frac{\mathrm{N}}{100 \% \pi}$ solution. Low oxygen ranged between 0.50 and 1 cc. per liter.
} 
but later, as the animals became more affected, this response also decreased to zero some time before death occurred.

As the positive rheotactic movement decreases either the negative or indefinite reactions must increase. Under normal conditions it has been shown that in stream isopods the negative rather than the indefinite reaction tends to be given in cases of low positive response. But little evidence was forthcoming concerning the relative metabolic condition of the animal giving highly positive or highly negative responses.

Under experimental conditions when the positive response is cut by depressing agents some evidence is available and is given in table 8. The high positive response may give way directly to a state of high indefiniteness as in the first, sixth, seventh and ninth instances cited in the table. But when the negative response is increased it stands intermediate between the two and when it is given under these conditions the efficiency has always decreased. Later with further decrease in efficiency the reaction becomes largely indefinite. The tenth item shows that this

TABLE 8

Showing the relative effect on the sign of the rheotactic reaction when the metabolic rate is known to have been reduced enough to cause an intermediate rate of efficiency

\begin{tabular}{|c|c|c|c|c|c|}
\hline ISOPOD NO. & $\begin{array}{c}\text { CAUBE OF } \\
\text { DEPRESSION }\end{array}$ & $\begin{array}{c}\text { EFFECT ON } \\
\text { POSITIVENESG }\end{array}$ & $\begin{array}{c}\text { EFFECT ON } \\
\text { NEGATIVENESB }\end{array}$ & $\begin{array}{c}\text { DFFECT ON } \\
\text { INDEFINITENESS }\end{array}$ & $\begin{array}{l}\text { CONDITION OF } \\
\text { RATM OF EFFI- } \\
\text { CIENCY }\end{array}$ \\
\hline I & $\mathrm{KCN}$ & decreased & unaffected & increased & intermediate \\
\hline II & molting ${ }^{2}$ & decreased & increased & increased later & intermediate \\
\hline & $\mathrm{KCN}$ & decreased & increased & increased later & intermediate \\
\hline \multirow[t]{2}{*}{ VI } & fatigue & decreased & increased & increased & intermediate \\
\hline & $\mathrm{KCN}$ & decreased & increased & increased & intermediate \\
\hline VII & low $\mathrm{O}_{2}$ & decreased & unaffected & increased & intermediate \\
\hline VIII & low $\mathrm{O}_{2}$ & decreased & unaffected & increased & intermediate \\
\hline IX & low $\mathrm{O}_{2}$ & decreased & increased & unaffected & intermediate \\
\hline XI & low $\mathrm{O}_{2}$ & decreased & unaffected & increased & intermediate \\
\hline & $\begin{array}{l}\text { after } \\
\text { low } \mathrm{O}_{2}\end{array}$ & increasing & increased & decreasing & intermediate \\
\hline XVI & low $\mathrm{O}_{2}$ & decreased & increased & unaffected & intermediate \\
\hline
\end{tabular}

1 By 'intermediate' is meant a rate between that given when the isopod is highly positive and when it is almost completely indefinite.

2 In this instance molting resulted in death. 



Chart 5 The rheotactic and concussion responses of isopod no. XI. For methods of eharting, see chart 1, p. 275.

Chart $5 \mathrm{~A}$ The effect of molting on the positive response and efficiency in isopod no. XI. For detailed account, see p. 285. The system of charting is the same as that given in chart 1, p. 275 . The spaces on the base line represent days. 
holds whether the isopod is coming out from or going under the effect of the depressing agent.

This same state of affairs is shown in the tables of the preceding paper ${ }^{5}$ which deal with the effects of depressing agents. The data presented in these tables may be illustrated by the



Chart 6 The rheotactic and concussion responses of isopod no. XIV. For methods of charting, see chart 1, p. 275.

following responses taken from table 15 which shows the effect of high carbon dioxide and low oxygen upon rheotaxis in stream isopods. The results are in percentages of 80 trials:

1. Eighty-nine per cent positive; 7 per cent negative; 4 per cent indefinite.

${ }^{5}$ Allee '12, tables 11 , p. $299 ; 15$, p. $310 ; 16$, p. $312 ; 17$, p. $315 ; 18$, p. $315 ; 19$, p. 316 ; and 20 , p. 318 . 
2. Two days later 65 per cent positive; 25 per cent negative; 10 per cent indefinite.

3. Three days later 33 per cent positive; 23 per cent negative; 44 per cent indefinite.

That is, in the early stages of the effects of these depressants the isopod tends to show increased negative responses and later when the depression is more complete the greater number of responses are indefinite.

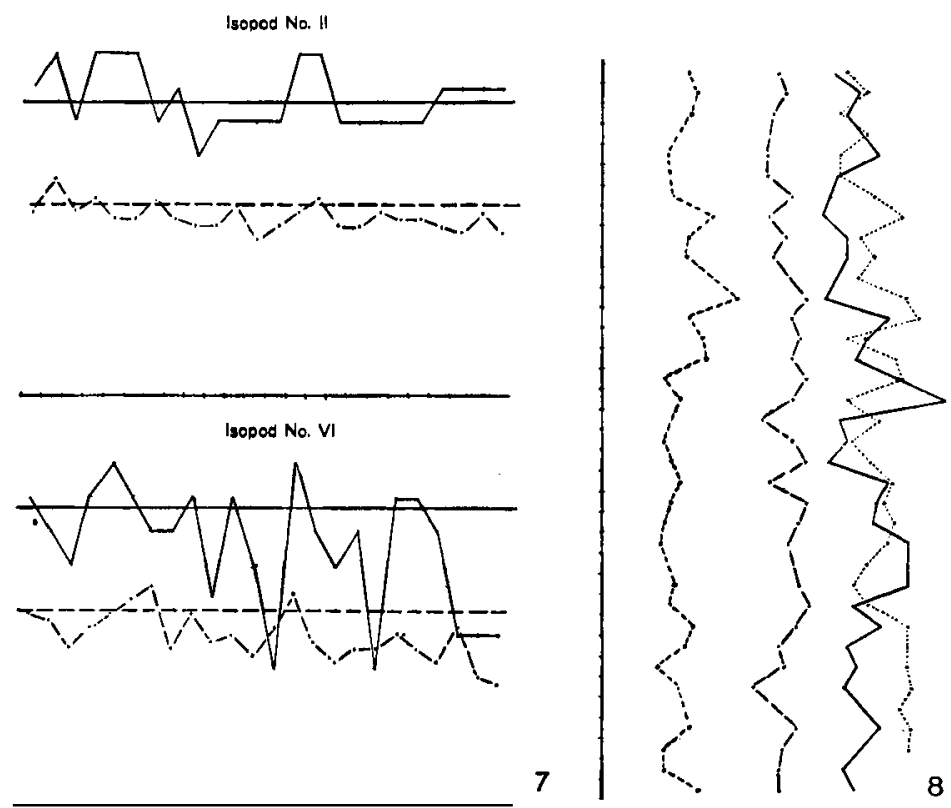

Chart 7 Showing the positive rheotactic response and efficiency of isopod nos. II and VI for twenty-four consecutive hours. The dots along the base line represent hours. For details of charting, see chart 1, p. 275.

Chart 8 A comparison of the positive reactions obtained from group tests with the average daily positiveness of three or more individual isopods. The group reactions are shown by the dotted line; the averaged individual responses are shown as chart 1, p. 275. For discussion, see p. 292.

\section{RHEOTAXIS DURING THE MOLTING PERIOD}

Wege ('11) gives the following account of the molting process in Asellus aquaticus:

Sometime before molting, usually twelve to twenty-four hours, the hypodermis begins to draw back from the body covering, whereby it 
plainly becomes folded in many places, a process wh ch may be due to growth. At the same time a new chitinous covering is excreted by the hypodermis. When this is strong enough the old covering splits around the body between the fourth and fifth thoracic segments. Then the hinder part, consisting of the covering of the thoracic segments and their appendages, is shed. Later the process is repeated for the forward part, head, four thoracic segments and their appendages. Twelve to twenty-four hours may intervene between the shedding of the hinder and forward parts. This process usually but not always takes place at night.

Wege did not find, as did Ost ('06) for Porcellio, any cases of autotomy, although he observed about a hundred animals.

The discarded covering is very thin and of a milky white color and consists mostly of chitin. The molting process goes on through life. The time interval between molts is usually from eight to thirty days, although over sixty days may elapse. The variation depends upon the age of the animal, temperature of the medium and the time of year. The interval increases with age and with winter, irrespective of the temperature. Wege's observations were carried on from October to the last of December in an evenly heated room, yet the interval increased for adults. The effect of temperature was still more marked for the intervals were much longer when the animals were kept in an unheated cellar.

This description of Wege's is more detailed than that of Zuelzer ('07). Her account agrees in essential features with that just given except that she observed that one to two days might elapse between the molting of the anterior and posterior parts.

In my observations on the molting process in Asellus communis I have no data to offer regarding the cause of variation in the interval between molts. In the main the process seems to resemble closely that described by Wege for $A$. aquaticus. However there are a few important exceptions. Thus in Asellus communis either the anterior or posterior part may shed its covering first and as long as four days may elapse between the molting of the halves. While this is the typical process yet the molting may occur by segments or even parts of a segment may break off and the molt extend over several days. In one instance the isopod molted all but the abdominal covering, which 
was molted piecemeal and was not entirely finished until nine days later. In another instance the antennae and head shed their covering although the general molt did not occur until seven days later.

The general effect of the molting period upon rheotaxis is shown in table 9 ; it is best illustrated by the following account taken from notes made at the time of the first observed molting of isopod no. XI (see also charts 5 and 5 a). This isopod was a male, $12 \mathrm{~mm}$. long, which averaged normally 86 per cent positive reactions. The molt began just after the first test of eleven individual trials which resulted in a response of 35 per cent positive, 35 per cent negative and 30 per cent indefinite, with an efficiency of 2.5 .

The covering broke between the fourth and fifth thoracic segments and the forward part was worked off over the head by a series of undulating motions of the body and by movements of the legs, both the posterior ones and those immediately concerned. It took seventy seconds to complete the process. One of the antennae that had been dragging before the molt occurred was dropped off with the exuvia. Immediately after the molt the fore legs were noticeably smaller than usual. During the process the isopod stayed in one place and disregarded, all currents. A current set up immediately after the molt was completed was also disregarded. After about two minutes in the same place the isopod moved across the pan and stopped in an angle $17 \mathrm{~cm}$. away. It rested there quietly for seventeen minutes when it was again tested ten times for rheotactic reaction. No movement occurred. At thirty minutes after molting ten trials showed 30 per cent positive, 60 per cent indefinite and 10 per cent no response, with an efficiency of 2.4 .

At this time the isopod was much more sensitive to touch stimuli than usual. In the response just given it twice ran into another isopod with its antennae and jumped back over a centimeter each time, although usually there would have been almost no reaction.

Three hours after molting the response was 70 per cent positive, 10 per cent indefinite and 20 per cent no reaction. The 
TABLE 9

Showing the rheotactic and concussion responses at the time of molting. The interval between molts expressed in days is given in the second column, the interval preceding the first observed molt is given as over the appropriate number of days; thus, in number $I$ the first molt occurred after fourteen days of observation and the interval is listed as being over fourteen days. The starred numbers indicate that these figures are repeated in the preceding or succeeding line of the table due to the short time interval between the anterior and posterior molts

\begin{tabular}{|c|c|c|c|c|c|c|c|c|c|c|c|c|c|}
\hline \multirow[b]{2}{*}{ 总 } & \multirow{2}{*}{  } & \multirow[b]{2}{*}{ 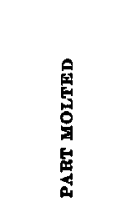 } & \multicolumn{3}{|c|}{$\begin{array}{l}\text { PERCENTAGE OF POSI- } \\
\text { TIVE REAPONSES }\end{array}$} & \multicolumn{3}{|c|}{ EFFICIENCY } & \multicolumn{3}{|c|}{$\begin{array}{c}\text { VIGOR OF BHOCK } \\
\text { REACTION } \\
\end{array}$} & \multirow{2}{*}{\multicolumn{2}{|c|}{ 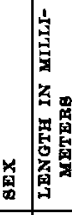 }} \\
\hline & & & 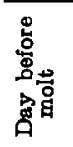 & 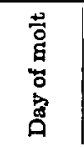 & 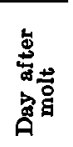 &  & 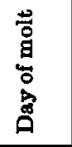 & 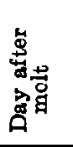 & 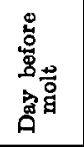 & 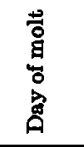 & 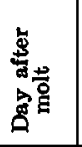 & & \\
\hline $\mathbf{I}$ & over & & & & & & & & & & & & \\
\hline & 14 & $\begin{array}{l}\text { anterior } \\
\text { all }\end{array}$ & 90 & & $\begin{array}{l}100 \\
100\end{array}$ & 2.6 & & 2.8 & 10 & 195 & & & \\
\hline & 13 & posterior & $\begin{array}{r}90 \\
100\end{array}$ & $\begin{array}{l}90 \\
60^{*}\end{array}$ & $\begin{array}{l}100 \\
100^{*}\end{array}$ & $\begin{array}{l}2.7 \\
3.0\end{array}$ & $\begin{array}{l}2.4 \\
2.8^{*}\end{array}$ & $\begin{array}{l}2.5 \\
4.0^{*}\end{array}$ & $\begin{array}{l}1.0 \\
1.2\end{array}$ & $0.15^{*}$ & $1.1^{*}$ & & \\
\hline & 1 & anterior & $60^{*}$ & $100^{*}$ & 100 & $2.8^{*}$ & $4.0^{*}$ & 2.8 & $0.15 *$ & $1.1^{*}$ & & & \\
\hline & $28^{1}$ & posterior & 50 & 30 & & 1.3 & 1.2 & & 0.25 & 0.6 & & $\%$ & 7 \\
\hline II & $\begin{array}{c}\text { over } \\
70\end{array}$ & & & & & & & & & & & & 10 \\
\hline III & $\begin{array}{c}\text { over } \\
14\end{array}$ & posterior & 90 & 90* & $80^{*}$ & 2.6 & $2.8^{*}$ & $2.9^{*}$ & & & & & \\
\hline & & anterior & $90^{*}$ & $80^{*}$ & 90 & $2.8^{*}$ & $2.9^{*}$ & 2.6 & & & & \% & $\gamma$ \\
\hline IV & over & & & & & & & & & & & & \\
\hline & 28 & posterior & 90 & $30^{* 3}$ & $90^{*}$ & 2.8 & $3.0^{*}$ & $2.9^{*}$ & & $2.0^{*}$ & $1.2^{*}$ & & \\
\hline & 1 & anterior & $30^{*}$ & $90^{*}$ & $20^{*}$ & $3.0^{*}$ & $2.9^{*}$ & 2.8 & $2.0^{*}$ & 1.2* & & & \\
\hline & 29 & anterior 4 & 90 & 70 & 90 & 2.8 & 2.0 & 2.6 & 1.0 & 1.7 & & $\sigma^{\prime \prime}$ & \\
\hline $\mathrm{V}$ & $\begin{array}{c}\text { over } \\
27\end{array}$ & posterior & 40 & $40^{*}$ & $40^{*}$ & 1.9 & $1.8^{*}$ & $2.0^{*}$ & & & & & \\
\hline & 1 & anterior & $40^{*}$ & $40^{*}$ & 60 & $1.8^{*}$ & $2.0^{*}$ & 2.0 & & 0.4 & 1.0 & $0^{7}$ & 10 \\
\hline VI & $\begin{array}{c}\text { Over } \\
42\end{array}$ & all & 90 & 100 & $40^{5}$ & 2.5 & 3.9 & 2.8 & & & & ㅇ & 11 \\
\hline VII & $\begin{array}{c}\text { over } \\
44\end{array}$ & all & 90 & 40 & 70 & 3.2 & 3.6 & 2.6 & 1.55 & 1.65 & 1.55 & $\sigma^{7}$ & 11 \\
\hline VIII & $\begin{array}{c}\text { over } \\
24^{6}\end{array}$ & & & & & & & & & & & $0^{x}$ & 10 \\
\hline IX & over & & & & & & & & & & & & \\
\hline & 1 & anteri & 70 & 0 & 60 & 3.9 & 4.0 & 2.6 & & & & & \\
\hline & $2^{7}$ & posterior & 90 & 90 & 30 & 3.3 & 2.9 & 3.9 & & & & 9 & 11 \\
\hline $\mathbf{X}$ & $\begin{array}{c}\text { over } \\
1\end{array}$ & & 80 & 90 & 80 & 2.5 & 2.8 & 2.8 & & & & & \\
\hline & 3 & posterior & 90 & $0^{8}$ & & 2.6 & 0.0 & & & & & \% & 9 \\
\hline
\end{tabular}


TABLE 9-Continued

\begin{tabular}{|c|c|c|c|c|c|c|c|c|c|c|c|c|c|}
\hline \multirow{2}{*}{ 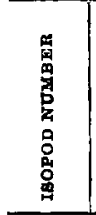 } & \multirow{2}{*}{ 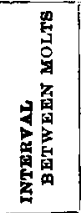 } & \multirow[b]{2}{*}{ 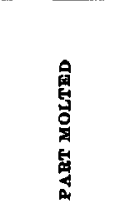 } & \multicolumn{3}{|c|}{$\begin{array}{l}\text { PERCENTAGE OF POBI- } \\
\text { TIVE REBPONARS }\end{array}$} & \multicolumn{3}{|c|}{ BFFICIENCY } & \multicolumn{3}{|c|}{$\begin{array}{l}\text { VIGOR OF BHOCK } \\
\text { REACTION }\end{array}$} & \multirow{2}{*}{\multicolumn{2}{|c|}{ 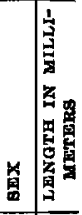 }} \\
\hline & & & 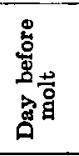 & 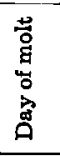 & 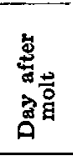 & 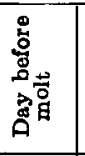 & 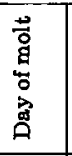 & 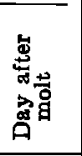 &  & 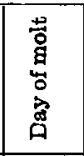 & 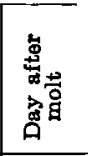 & & \\
\hline \multirow{3}{*}{$\mathrm{XI}$} & & terior & & 0 & $100^{*}$ & & 0.0 & $3.0^{*}$ & & & & & \\
\hline & 2 & & $100^{*}$ & 40 & 80 & $3.0^{*}$ & 2.6 & 2.7 & & & & & \\
\hline & 31 & all & 80 & 20 & 80 & 2.0 & 2.2 & 3.0 & 1.45 & 1.45 & 1.05 & o & 12 \\
\hline \multirow{4}{*}{$\begin{array}{r}\mathrm{XII} \\
\mathrm{XIII}\end{array}$} & $\begin{array}{c}\text { over } \\
40^{9}\end{array}$ & & & & & & & & & & & 우 & \\
\hline & over & & & & & & & & & & & & \\
\hline & 1 & anterior & & $70^{*}$ & $50^{*}$ & & $3.2 *$ & $2.1^{*}$ & & & & & \\
\hline & $1^{10}$ & posterior & $70^{*}$ & $50^{*}$ & $30^{*}$ & $3.2^{*}$ & $2.1^{*}$ & 1.8 & & & & $\sigma^{2}$ & 13 \\
\hline \multirow{3}{*}{ XIV } & over & & & & & & & & & & & & \\
\hline & 44 & post & 60 & 50 & $70^{*}$ & 2.3 & 2.3 & $2.0^{*}$ & & & & & \\
\hline & 2 & anterior & $70^{*}$ & $60^{11}$ & & $2.0^{*}$ & 2.4 & & & & & $\sigma^{3}$ & 10 \\
\hline \multirow{6}{*}{$\mathrm{XV}$} & over & & & & & & & & & & & & \\
\hline & 1 & po & 20 & 90 & 90 & 2.4 & 2.7 & 2.9 & & 1.2 & & & \\
\hline & 3 & anteric & 90 & 10 & 40 & 2.9 & 3.8 & 2.1 & & 2.4 & & & \\
\hline & 21 & al & 100 & 70 & 80 & 2.0 & 2.4 & 2.9 & & & & & \\
\hline & 7. & $\mathbf{a}$ & 70 & 60 & 70 & 2.0 & 2.5 & 2.5 & 0.25 & 0.9 & & & \\
\hline & 17 & middle $^{12}$ & 60 & 30 & 50 & 2.1 & 2.0 & 2.9 & 1.35 & 0.3 & 1.6 & \% & 6 \\
\hline \multirow{2}{*}{ XVII } & & anterior & & $40^{*}$ & $40^{*}$ & & $2.8^{*}$ & $2.9^{*}$ & & 1.51 & & & \\
\hline & 1 & posterior & $40^{*}$ & $40^{*}$ & 30 & $2.8^{*}$ & $2.9^{*}$ & 2.1 & & 1.45 & & $0^{3}$ & 9 \\
\hline \multirow[t]{3}{*}{ XVIII } & over & & & & & & & & & & & & \\
\hline & 8 & poster & 80 & 20 & & 2.7 & 2.0 & & & & & & \\
\hline & 2 & anter & & 80 & 50 & & 2.2 & 2.5 & & 0.75 & 1.2 & & 5 \\
\hline \multirow{3}{*}{$\mathbf{X I X}$} & over & & & & & & & & & & & & \\
\hline & 11 & & 40 & $20^{*}$ & $60^{*}$ & 2.9 & $3.1 *$ & $3.1^{*}$ & 1.3 & $1.85^{*}$ & $1.65^{*}$ & & \\
\hline & 1 & anterior & $20^{*}$ & $60^{*}$ & 90 & $3.1^{*}$ & $3.1 *$ & 2.9 & $1.85^{\prime \prime}$ & $1.65^{*}$ & 1.15 & 9 & 10 \\
\hline $\mathbf{X X}$ & 3 & all & 70 & 80 & 90 & 2.6 & 2.9 & 2.1 & 1.4 & 1.2 & & $\left|0^{2}\right|$ & 8 \\
\hline
\end{tabular}

1 Trying to molt for eleven days, but was weakened by exposure to potassium cyanide. Died from molting.

2 Died from molting trouble.

${ }^{8}$ Molted within six hours before the trial was made.

${ }^{4}$ Molted posterior part piecemeal and did not finish until nine days later.

5 Put in potassium cyanide which probably accounts for the depression.

${ }^{6}$ Molted piecemeal.

${ }^{7}$ Did not molt again in the forty-four days it was watched.

Died from molting.

No molt seen in forty days although piecemeal molting may have occurred.

${ }^{10}$ No more molts in thirty-one days before death.

" Escaped from petri dish during interval before concussion tests.

12 Molted piecemeal. 
efficiency was 2.1. Two hours later the response was 90 per cent positive, 10 per cent no reaction, efficiency 2.8. This last trial was characterized by steady slow movements and quick orienting, the latter seldom taking over five seconds.

In this case the molt of the posterior end occurred two days later, after 9 P.M. At nine the response was 40 per cent positive, 40 per cent negative, 20 per cent indefinite, efficiency 2.6 . The next morning the response was 80 per cent positive, 20 per cent negative, efficiency 2.7. On the morning after the next molt, thirty-one days later, this isopod would start positive and then quickly turn negative as if the current pressure against the more sensitive covering were painful.

Isopods stand higher from the bottom when nearing molting, which is probably due to the increasing stiffness of their legs. This makes resistance to the current more difficult. At this time the posterior legs appear harder to move and may become tangled, thus throwing the isopod as it tries to crawl. Immediately after molting they are thrown from their feet more easily than during other parts of the cycle.

The more gradual molts mentioned above may also affect the rheotactic reaction. Thus in one instance an isopod (no. IV) molted the fourth thoracic segment and legs while its response was being tested. This occurred about thirty to thirty-six hours after the anterior molt and was accompanied by a cut of 20 per cent in the positive reaction. . Another tendency is indicated by the molt in isopod no. V (table 9). This animal had been injured in handling and before molting gave a high percentage of indefinite responses but afterward the percentage of positive reactions was suddenly and markedly increased.

As is seen in the account for the molting observed in isopod no. XI, the effect of the molting lasted for about five hours after the actual ecydsis took place. If the period extended as long beforehand it would make the time during which rheotaxis was affected by the molting process extend over a period of about ten hours. It is conceivable that the general morning tests such as were usually made might not hit this period at all. Sometimes this is the case, as is illustrated in the molting of no. VII (table 
9, chart 4) but usually there was a more or less decided decrease in the percentage of positiveness (table 9 and charts). When this occurred there was nearly always a decrease in the efficiency of the reaction and an increase in the negative response.

Sometimes there was an increase in the vigor of the concussion response at this period but this is too infrequent and the data on this point too meager to warrant a definite statement on this relationship.

\section{SUMMARY OF RESULTS}

I. Relation between efficiency and the sign of rheotactic response of stream isopods:

1. In the daily variations to the current the efficiency of movement tended to vary with the percentage of positive reactions (p. 268).

2. The larger variations of the positive reactions are usually accompanied by similar variations in efficiency (charts 1 to 8).

3. Low efficiency is accompanied by a low percentage of positive and negative and by a high percentage of indefinite rheotactic reactions (p. 270).

4. High efficiency is always accompanied by a low percentage of indefinite responses; usually by a low percentage of negative and a high percentage of positive reactions (p. 270).

5. In exceptional individuals high efficiency may be accompanied by either low or high percentage of positive responses (p. 272).

6. Under the influence of potassium cyanide and low oxygen both the positive responses and the rate of efficiency is decreased. The rheotactic reactions may go directly from a preponderance of positive to one of indefinite reactions, or there may be an interval of increased negative response. In the latter case the increased negative response always accompanies an intermediate rate of efficiency '(p. 280).

7. At the time of molting, sensitiveness to currents of water is reduced to zero, but recovery is rapid. The rheotactic reactions may be affected for a ten-hour interval at each molt. During this time both the number of positive reactions and the 
efficiency is decreased while the number of negative reactions is often increased (p. 285).

II. Relation between vigor of response to concussion and rheotaxis:

1. In the daily variations there is no apparent relationship between the vigor of the response to shock and either the sign or the efficiency of the rheotactic reaction (p. 268).

2 . The greater variations show no more relation than do the smaller ones (charts 1-6, pp. 275-282).

3 . The average vigor of shock reaction which accompanies low and high efficiency; low and high percentage of positive reactions; and low and high percentage of indefinite reactions are practically identical. The vigor of concussion response that accompanies a high percentage of negative reactions is slightly higher than the others (pp. 269-273).

4. Under the influence of potassium cyanide and low oxygen the vigor of the shock reaction often increases at first as the percentage of positive responses and rate of efficiency decrease, but later decreases and becomes zero before death occurs (p. 279).

5. There is some evidence of an increased sensitiveness to shock stimuli during the molting period (p. 289).

III. More variations occur in the percentage of positive responses than can be accounted for by variations of known external or internal factors (p. 274).

IV. Potassium cyanide and low oxygen act at different rates in different isopods but in all there is finally a depression reaction from which the isopods may recover if placed in normal conditions (p. 279).

$\mathrm{V}$. The length of the molting cycle varies greatly in different individuals and in successive cycles of the same individual and causes certain variations in the rheotactic reaction (p. 285).

\section{DISCUSSION}

With these results in mind it becomes pertinent to inquire into the relation between the reactions of individual stream and pond isopods. Nothing can be said of the limits of individual variation among pond mores because no work as yet has been done 
from this viewpoint, but regarding the efficiency of movement of pond isopods there is some data. By comparing the graphs of thirty-five individual trials ${ }^{6}$ of stream with fifty of pond isopods it appears that the relative vigor of the pond is about half that of the stream mores, while on the average the positive rheotactic response is about three-eighths as strong. Here again there is apparent agreement between the degree of positiveness and the rate of efficiency.

The response to concussion failed to furnish an exact method for testing the metabolic state. This was first suggested in the responses listed in table 3. Further evidence is found in charts 1 to 6 , which show that the variations of the vigor of the reaction to shock oppose those of positiveness and efficiency almost as often as they agree; also by the fact (tables 4,5 and 6 ) that practically the same vigor of concussion is given with both high and low positiveness, high and low indefiniteness and high and low efficiency. It seems probable that the vigor of the concussion reaction varies inversely as the thigmotactic response rather than directly as the rheotactic reaction.

In the early periods of depression the vigor of the concussion response often increases. This action corresponds with that usually given during early stages of the action of depressing agents. The cause of the increased reaction is now generally regarded as being due to the decrease of the normal inhibitory power of the nervous system (Sherrington '06, p. 106). Later with increased action of the depressing agent this decrease in the action of the inhibiting nerves gives way to depression of the entire nervous system. This period corresponds to the time when weakened shock responses were given in the later stages of depression.

In the previous experiments ('12, p. 285) it was shown that stream isopods cannot permanently maintain themselves in a stream where they cannot withstand the current during the weakened responses of the breeding season. From the present experiments it appears that the molting period offers for brief

6 These graphs are those from which figures 1 and 2 (pp. 278, 291) of the preceding paper were taken. 
but frequently recurring periods, equally weakened responses, and hence is of equal importance in the ecology of the species. The minor variations in positiveness are probably of little ecological importance. The isopods that sometimes showed a high percentage of negativeness gave on the average (table 7) as many positive as negative reactions. This means that for these isopods the sign of the rheotactic reaction is of practically no importance in maintaining the position in the stream.

Following the experiments upon the rheotactic reactions of individual isopods the question arises as to the relation of averaged results obtained by this method with those obtained by group tests as performed in preceding experiments ('12). The two types of results may be seen plotted in chart 8 (p. 283). The group responses are taken from table 2, page 280 (Allee '12). The chart shows that the results given by the two methods are essentially the same.

Four of the twenty isopods tested showed a tendency to give a large number of negative reactions under normal conditions. This shows why five stream isopods taken at random give a positive response of from 70 to 80 per cent. The chances are that four of the five will give a positive response of from 80 to 100 per cent averaging some place in the upper eighties. The other will give a response of about 50 per cent positive which will cause the average reaction to be between 70 and 80 per cent positive.

By substituting the plan of individual for group tests the amount of individual variation becomes emphasized. In the highly positive isopods this consists of 20 per cent variation both in the degree of positiveness and in the efficiency of the response. In other and more exceptional cases the range is still greater. It also shows that in some stream isopods a high negative response may accompany a high rate of efficiency although this condition is too infrequent to greatly affect average results.

In the preceding paper ('12, pp. 338-39) it was shown that the degree of positiveness depends upon the rate of metabolism and can be controlled by certain factors known to affect animal metabolism. In the present series of experiments it has been 
shown (table 8, p. 280) that under experimental conditions positive isopods may come to give negative reactions when the efficiency or vigor of response is intermediate between that which usually accompanies high positiveness and high indefiniteness.

Then if we use the degree of positiveness as an index of the physiological state of the stream isopods we shall have the following results:

\begin{tabular}{|c|c|c|}
\hline RHEOTAXIS & EFTICIENCY & PERIOD WHEN GIVEN \\
\hline $\operatorname{High}+$, low - and $\alpha$ & high & $\begin{array}{l}\text { us u a ll y accompanies optimum } \\
\text { conditions }\end{array}$ \\
\hline $\begin{array}{l}\text { Lowered }+ \text {, heightened - and } \\
\text { low } \alpha\end{array}$ & high & $\begin{array}{l}\text { sometimes accompanies appar- } \\
\text { ently optimum conditions }\end{array}$ \\
\hline $\begin{array}{l}\text { Lowered }+ \text {, heightened - and } \\
\quad \text { low } \alpha\end{array}$ & intermediate & $\begin{array}{l}\text { near beginning or close of peri- } \\
\text { ods of depression }\end{array}$ \\
\hline $\begin{array}{l}\text { Low }+ \text { and }- \text {, high } \alpha \\
\text { Low }+,-, \text { and } \alpha \text { high } 0\end{array}$ & $\begin{array}{l}\text { low } \\
\text { zero }\end{array}$ & $\begin{array}{l}\text { at periods of strong depression } \\
\text { at times of extreme depression }\end{array}$ \\
\hline $\begin{array}{l}\text { Minor variations of any of the } \\
\text { above }\end{array}$ & & $\begin{array}{l}\text { occur when the conditions are } \\
\text { apparently uniform }\end{array}$ \\
\hline
\end{tabular}

That is, the work with individuals has shown that in the physiological states that accompany the highest efficiency there is something as yet unanalyzed that sometimes causes negative responses where positive reactions are usually given. Also that the varying physiological states that produce the minor variations are as yet inexplicable in their entirety (cf. Pearl '02, with Planaria and Jennings '02, with Stentor) although each class may be in part explained by the influence of the molting period. One other factor that may affect the minor variation is the fact that the isopods tend to continue in the direction in which they are started regardless of the response they will ultimately make ('12, p. 276), so some of the variations may be due to this error in the method. It is probable that factors enter into the control of the positive rheotactic response other than the rate of metabolism of the organism. Thus during the molting period there is an interval when the mechanical difficulties are such that movement is limited regardless of the metabolic condition of the isopod. Yet on the average the data at hand strongly indicate that the degree of positiveness and the efficiency of Asellus com- 
munis in a water current depend primarily upon the rate of metabolism.

It is possible to measure the rate of metabolism by the survival time in a standard strength of potassium cyanide (Child '13, p. 155). Since the purpose of these experiments was to study the extent of variations in individual isopods this procedure was obviously impossible. Now that something has been learned concerning the amount of individual variation, the cyanide method can be used to advantage.

I am indebted to Dr. V. E. Shelford and Dr. C. M. Child for criticism and suggestions during the progress of this work; to Dr. Shelford also for reading the manuscript; to M. H. Allee for assistance with certain of the experiments; to B. W. Benedict for making the concussion apparatus without charge; and to Dr. C. F. Hottes for furnishing laboratory facilities for the prosecution of the work.

April, 1913. 


\section{BIBLIOGRAPHY}

Allee, W. C. 1912 An experimental analygis of the relation between physiological states and rheotaxis in Isopoda. Jour. Exp. Zoöl., vol. 13, pp. 269-344.

BANTA, A. M. 1910 A comparison of the reactions of a species of surface isopod with those of a subterranean species. Jour. Exp. Zoöl., vol. 8, pp. $439-488$.

BARtow, Ed. 1906 Bull. no. 6, Ill. State Water Survey.

BонN, G. 1903 a Sur les mouvements oscillatoires des Convoluta roscoffensis C.r. Ac. Sci., Paris, vol. 137, p. 576.

$1903 \mathrm{~b}$ Les convoluta roscoffensis et la theorie des causes actuelles. Bull. d. Hist. Nat., vol. 9, pp. 352-64.

CHILd, C. M. 1913 Studies on the dynamics of morphogenesis and inheritance in experimental reproduction. $V$. The relation between resistance to depressing agents and rate of metabolism in Planaria dorotocephala and its value as a method of investigation. Jour. Exp. Zoöl., vol. 14, no. 2, pp. 153-206.

Dawson, J. 1911 The biology of Physa. Behavior Monographs, vol. 1, no.4, $120 \mathrm{pp}$.

Holmes, S. J. 1911 The evolution of animal intelligence. New York. 296 pp.

Jennings, H. S. 1912 Reactions to stimuli in unicellular organisms. IX. On the behavior of infusoria. Am. Jour. Physiol., vol. 8, pp. 23-61.

1906 Behavior of the lower organisms. $366 \mathrm{pp}$. New York.

Loes, J. 1905 Studies in general physiology. 2 parts. Chicago.

Marsi, M. C. 1910 Notes on the dissolved content of waters in its effect on fishes. Bull. Bur. Fish., 1908. (Internat. Fisheries Congress) pp. 893-906.

Mast, S. O. 1911 Light and the behavior of organisms. $410 \mathrm{pp.} \mathrm{New} \mathrm{York.}$

Ost, J. 1906 Zur Kenntnis der Regeneration der Extremitäten bei den Arthropoden. Arch. Entw. Mech., Bd. 22, pp. 289-324.

Pearl, R. 1903 The movements and reactions of fresh water planarians. A study in animal behavior. Qr. Jour. Micr. Sci., vol. 46, pp. 509-714.

SEMPER, K. 1881 Animal life. $467 \mathrm{pp}$. New York.

SHelford, V. E. 1911 Ecological succession. I. Stream fishes and the method of physiological analysis. Biol. Bull., vol. 21, pp. 9-36.

1912 Ecological succession. V. Aspects of physiological classification. Ibid, vol. 23 , pp. 331-370.

Shelford, V. E., AND Allee, W. C. 1913 The reactions of fishes to gradients of dissolved atmospheric gases. Jour. Exp. Zoöl., vol. 14, pp. 207-266.

Sherrington, C. S. 1906 The integrative action of the nervous system. 411 pp. New York.

WeGs, W. 1911 Morphologische und experimentelle Studien an Asellus aquaticus. Autotomie, Häutung, und Regeneration. Zool. Jahrb., Bd. 30, Allg. Zool, und Physiol., pp. 217-320.

ZonlzEr, M. 1907 Uteber den Einfluss der Regeneration auf die Wachstumsgeschwindigkeit von Asellus aquaticus L. Arch. Entw. Mech, der Organism, Bd. 25, pp. 361-397. 